REVISTA CIENCIAS BIOMÉDICAS

ARTÍCULOS ORIGINALES

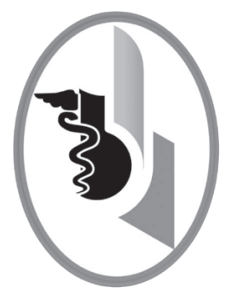

\title{
EFECTIVIDAD DE LA TERAPIA ANTIRRETROVIRAL DE GRAN ACTIVIDAD (TARGA) EN PACIENTES VIH POSITIVOS INGRESADOS AL PROGRAMA DE TRATAMIENTO DE LA IPS ATENCIÓN INTEGRAL EN LA CIUDAD DE CARTAGENA. COLOMBIA
}

\author{
EFFECTIVENESS OF ANTIRETROVIRAL THERAPY (HAART) \\ IN HIV POSITIVE PATIENTS ADMITTED TO THE TREATMENT \\ PROGRAM OF "ATENCION INTEGRAL IPS" IN THE CITY OF \\ CARTAGENA. COLOMBIA
}

Torres Mora Gustavo ${ }^{1}$ Moreno Grau Álvaro² Moreno Hernández Diego 3 Berrocal Almanza Luis Carlos ${ }^{4}$ Ramos Clason Enrique Carlos ${ }^{5}$

Correspondencia: gtorresmora@hotmail.com Recibido para evaluación: enero - 22 - 2011. Aceptado para publicación: marzo - 11 - 2011

\section{RESUMEN}

Introducción: a pesar que la infección por VIH/SIDA es uno de los principales problemas de salud en Colombia, son escasos los estudios clínicos y epidemiológicos que evalúen el tratamiento de estos pacientes. La ciudad de Cartagena de Indias, posee condiciones propicias para la infección por VIH como su condición de distrito turístico, epicentro de cambios demográficos y sociales que están vinculados con un alto riesgo de infección por VIH (4), no posee estudios que evalúen la efectividad de los tratamientos antirretrovirales.

Objetivo: estimar la efectividad a seis meses, de la terapia TARGA en pacientes VIH positivo ingresados a un programa de tratamiento de una IPS de la ciudad.

Metodología: estudio descriptivo retrospectivo en el que se analizaron todos los pacientes adscritos al programa de VIH/SIDA en la IPS "Atención integral" entre enero de 2007 a Julio de 2010. Se estudiaron variables demográficas como sexo edad, peso, índice de masa corporal, los diferentes esquemas antirretrovirales, conteo de linfocitos CD4, carga viral.

Resultados: se encontraron 167 pacientes adscritos al programa, de estos se excluyeron 9 casos por no haber realizado la TARGA y 96 por no presentar el reporte de la carga viral antes o después del tratamiento; en total se analizaron 62 casos. El 59,7\% era de sexo masculino, el promedio de edad fue de 35 años con desviación estándar (DE) de

1 Médico. Estudiante de postgrado. Medicina interna. Facultad de Medicina. Universidad de Cartagena. Colombia.

2 Médico. Especialista en Reumatología. Docente asistente. Facultad de Medicina. Universidad de Cartagena. Colombia.

3 Médico. Especialista en Medicina Interna. Facultad de Medicina. Universidad de Cartagena. Colombia.

4 Bacteriólogo. Máster en Salud Pública Internacional. Candidato a doctor en Epidemiologia Funcional y Molecular de Enfermedades Infecciosas. Universidad Libre de Berlín (Alemania).

5 Médico. Magíster en Salud Pública. Profesor de cátedra Departamento de Investigaciones. Facultad de Medicina. Universidad de Cartagena. Colombia. 
9,4 años. El 49,5\% de los casos tenía 30 años o menos; la edad mínima fue de 20 y la máxima de 58 años en promedio el $44,4 \%$ de las historias clínicas no tenía reportes de alguno de los paraclínicos de ingreso. El 16,1\% de los pacientes tenía anemia, el 19,4\% hipertrigliridemia, $17,7 \%$ hipercolesterolemia y $21,0 \%$ niveles bajos de colesterol HDL. Los cinco esquemas de TARGA más frecuentemente utilizados fueron: Lamivudina Estavudina Nevirapina con $29,0 \%$ de los casos, Lamivudina Zidovudina Efavirenz 19,4\%, Lamivudina Estavudina Kaletra $11,3 \%$ y Lamivudina Abacavir Kaletra 8,1\%. La efectividad de la TARGA teniendo en cuenta los parámetros anteriores muestra que existe una disminución estadísticamente significativa de la carga viral. La proporción de efectividad general de la TARGA fue de 9,9\% para disminución del recuento de linfocitos T CD4 (+) y del 58,9\% para disminución de la carga viral

Conclusión: la evaluación de la terapia antirretroviral en el paciente con VIH/SIDA es un punto neurálgico de la atención de estos pacientes y al mismo tiempo el menos estudiado. Nuestra investigación pretende resaltar este tema e invitar a los interesados a realizar estudios prospectivos al respecto, los cuales incidirán positivamente en la salud de los pacientes, asignación de recursos gubernamentales, iniciativas encaminadas a la vigilancia y control de estos programas y reestructuraciones de los mismos. Rev. cienc.biomed. 2011; 2 (1): 44-53

\section{PALABRAS CLAVE}

Síndrome de inmunodeficiencia adquirida. Terapia antirretroviral altamente activa. Carga viral. Linfocitos T CD4-positivos. Guías de práctica clínica.

\section{SUMMARY}

Background: Although HIV infection / AIDS are one of the major health problems in Colombia, there are few clinical and epidemiological studies assessing the treatment of these patients. The city of Cartagena de Indias, has favorable conditions for infection with HIV because of their status as tourist district and for being an epicenter of social and demographic changes that are associated with an increased risk of HIV infection (4), however no studies have evaluated the effectiveness of antiretroviral treatment.

Aim: To estimate effectiveness of six months of HAART therapy in HIV patients admitted to a treatment program in a health center of the city.

Methods: Retrospective descriptive study that examined all patients assigned to the program for HIV / AIDS in the health center "Atencion integral" from January 2007 to July 2010. We studied demographic variables as sex, age, weight, body mass index, different antiretroviral schemes, CD4 count and viral load.

Results: There were 167 patients assigned to the program. Nine cases were excluded for failing to adherence HAART and 96 for not having the report of viral load before or after treatment. A total of 62 cases were analyzed. $59.7 \%$ were male, average age was 35 years with standard deviation (SD) of 9.4 years. $49.5 \%$ of patients were 30 years or less, the minimum age was 20 and maximum of 58 years. An average of $44.4 \%$ of medical charts had no reports of any of the initial labs. $16.1 \%$ of patients had anemia, $19.4 \%$ hipertrigliridemia $17.7 \%$ hypercholesterolemia and $21.0 \%$ low HDL cholesterol levels.

The five schemes more frequently used of HAART were Lamivudine Stavudine Nevirapine with $29.0 \%$ of cases, $19.4 \%$ Lamivudine Zidovudine Efavirenz, 11.3\% Kaletra $\circledR$ Stavudine Lamivudine and $8.1 \%$ Lamivudine Abacavir Kaletra $囚$. The effectiveness of HAART, taking into account the above parameters, shows that there is a statistically significant decrease in viral load. The proportion of overall effectiveness of HAART was 9.9\% for decrease in CD4 T lymphocyte count (+) and $58.9 \%$ for viral load decrease. Conclusión: The evaluation of antiretroviral therapy in patients with HIV/AIDS is a hub for the care of these patients and at the same time the least studied. Our research aims to highlight this issue and invite interested parties to carry out studies in this regard, which positively affect the health of patients, allocation of government resources, initiatives aimed at monitoring and monitoring of these programs and restructuring of the same. Rev.cienc.biomed. $2011 ; 2$ (1): 44-53

\section{KEYWORD}

Acquired Immunodeficiency Syndrome. Highly Active Antiretroviral Therapy. Viral load. CD4-positive T-lymphocytes. Practice guidelines. 


\section{INTRODUCCIÓN}

La infección por el Virus de la Inmunodeficiencia Humana (VIH) es uno de los principales problemas de salud pública a nivel mundial y nacional $(1,2,3)$. De la misma manera el tratamiento farmacológico de esta entidad implica un reto para la comunidad científica, dado los mecanismos de ataque del sistema inmune que posee este virus.

Desde la aprobación de la guía única de práctica clínica para el manejo del VIH y el modelo de gestión programática en VIH y el Síndrome de Inmunodeficiencia Adquirida (SIDA) en Colombia, se contempla la evaluación periódica de las terapias antirretrovirales recomendadas $(1,2)$. No obstante la información disponible de estudios clínico epidemiológicos al respecto es pobre.

En el periodo comprendido de 1983 a 2007 se han diagnosticado en Colombia cerca de 57.500 personas que viven con el VIH o han desarrollado la enfermedad del Síndrome de Inmunodeficiencia Adquirida (SIDA), 24.000 de estos han fallecido. La prevalencia de esta enfermedad estimada para personas entre 15 y 49 años es de $0,7 \%$, es decir cerca de 171.500 casos; aunque está claro que estas cifras implican un importante subregistro (1).

En Colombia se han incorporado al Plan Obligatorio de Salud (POS) todos los medicamentos y los procedimientos diagnósticos disponibles en el país para tales efectos $(1,2)$. Se estima que del total de personas diagnosticadas, 23.000 requieren tratamiento antirretroviral, del cual un $72 \%$ tiene cobertura para el tratamiento. El $75 \%$ de los pacientes que requieren terapia antirretroviral de gran actividad (TARGA) reciben los medicamentos que necesitan, y aproximadamente el $45 \%$ de ellos tienen dentro de sus esquemas medicamentos fuera del plan de beneficios del POS $(1,2)$.

La ciudad de Cartagena de Indias, no posee estudios que evalúen la efectividad de los tratamientos antirretrovirales, lo anterior a pesar de ser la ciudad donde fue reportado el primer caso de infección por VIH/SIDA del país en el año de 1983, además posee condiciones propicias para la infección por VIH como su condición de distrito turístico, epicentro de cambios demográficos y sociales que están vinculados con un alto riesgo de infección por VIH (4). Otros factores son la presencia de personas que pertenecen a grupos con alto nivel de vulnerabilidad lo que facilita su expansión. También hay que recalcar que el área del Caribe tiene las tasas más altas de infección por VIH fuera del África Sub Sahariana (3).

A la fecha, la mayor parte de los estudios que soportan las guías actuales de manejo de la enfermedad VIH-SIDA se han realizado en países industrializados. Aunque en el diseño de estas guías se han incluido resultados de ensayos clínicos aleatorios realizados en grupos de pacientes de diferentes lugares del mundo, su aplicabilidad en lugares con diferentes contextos epidemiológicos, características sociodemográficas y socioeconómicas no se ha evaluado ampliamente, teniendo en cuenta todos estos factores que podrían modificar el resultado de las terapias y el riesgo de progresión a SIDA.

En Cartagena no se han divulgado estudios sobre la atención del paciente con VIH/ SIDA en ninguno de los muchos programas de atención integral. Por tal razón surge la necesidad de estimar la efectividad de la terapia antirretroviral de gran actividad (TARGA) en Cartagena en un centro de atención integral que cuente con una amplia base de datos de pacientes con VIH/ SIDA bajo tratamiento. El objetivo de esta investigación es estimar la efectividad a seis meses, de la terapia TARGA en pacientes VIH positivo ingresados a un programa de tratamiento.

\section{MATERIALES Y MÉTODOS}

Se diseñó un estudio descriptivo retrospectivo, en el cual se seleccionaron como sujetos de estudio todos los pacientes con VIH/SIDA adscritos al programa de atención al VIH de la IPS Atención Integral de Cartagena entre enero de 2007 a julio de 2010 que hayan recibido la TARGA, mayores de 14 años, con disponibilidad de carga viral antes y después del tratamiento. Se excluyeron a todos los pacientes que abandonaron la 
Torres Mora Gustavo, Moreno Grau Álvaro, Moreno Hernández Diego, Berrocal Almanza Luis Carlos, Ramos Clason Enrique Carlos

terapia, fallecidos y con datos incompletos en la historia clínica. No se realizó un diseño muestral, dado que se tuvo acceso a la totalidad de casos adscritos al programa de atención al VIH de la IPS Atención Integral de Cartagena, en el periodo de estudio. La información se obtuvo de la revisión de las historias clínicas de los pacientes de estudio.

Análisis estadístico: se realizaron tablas y gráficos de frecuencia para las variables cualitativas; mientras que para las cuantitativas medidas de tendencia central y de dispersión. La efectividad fue expresada como el porcentaje de mejoría clínica en general y por esquema TARGA utilizada, se aplicó como prueba de hipótesis el test de Wilcoxon para muestras pareadas.

\section{RESULTADOS}

Durante el periodo de estudio se encontraron 167 pacientes adscritos al programa de atención al VIH de la IPS Atención Integral, de estos se excluyeron 9 casos por no haber realizado la TARGA y 96 por no presentar el reporte de la carga viral antes o después del tratamiento; en total se analizaron 62 casos.

El $59,7 \%$ era de sexo masculino, el promedio general de edad fue de 35 años con desviación estándar (DE) de 9,4 años. El 49,5\% de los casos tenía 30 años o menos; la edad mínima fue de 20 y la máxima de 58 años. El estadio del VIH y la fase SIDA más frecuente fueron el A2 y la FASE 3 respectivamente. Tabla N01.

\begin{tabular}{|c|c|c|}
\hline \multicolumn{3}{|c|}{$\begin{array}{c}\text { TABLA No } 1 \\
\text { DISTRIBUCIÓN DE LAS CARACTERÍSTICAS } \\
\text { GENERALES DE LOS PACIENTES }\end{array}$} \\
\hline & $\mathrm{n}$ & $\%$ \\
\hline \multicolumn{3}{|l|}{ Sexo } \\
\hline Femenino & 20 & 32,3 \\
\hline Masculino & 37 & 59,7 \\
\hline No determinado & 5 & 8,1 \\
\hline $\begin{array}{l}\text { Edad (Promedio } \pm \\
\text { DE) }\end{array}$ & $35 \pm 9,4$ & \\
\hline $20-25$ & 9 & 23,7 \\
\hline $26-30$ & 6 & 15,8 \\
\hline $31-35$ & 6 & 15,8 \\
\hline $36-40$ & 6 & 15,8 \\
\hline$\geq 41$ & 11 & 28,9 \\
\hline \multicolumn{3}{|l|}{ Estadio } \\
\hline VIH & 25 & 40,3 \\
\hline VIH FASE A1 & 2 & 3,2 \\
\hline VIH FASE A2 & 17 & 27,4 \\
\hline VIH FASE A3 & 6 & 9,7 \\
\hline SIDA & 37 & 59,7 \\
\hline FASE 1 & 1 & 1,6 \\
\hline FASE 2 & 12 & 19,4 \\
\hline FASE 3 & 24 & 38,7 \\
\hline
\end{tabular}

En promedio el $44,4 \%$ de las historias clínicas no tenía reportes de alguno de los paraclínicos de ingreso. El $16,1 \%$ de los pacientes tenía anemia, el 19,4\% hipertrigliridemia, $17,7 \%$ hipercolesterolemia y $21,0 \%$ niveles bajos de colesterol HDL. No se reportaron hiperglucemia ni alteraciones en los niveles de creatinina ni colesterol LDL. Tabla No 2.

Los cinco esquemas de TARGA más frecuentemente utilizados fueron: Lamivudina Estavudina Nevirapina con $29,0 \%$ de los casos; Lamivudina Zidovudina Efavirenz 19,4\%;

\begin{tabular}{|c|c|c|c|c|c|c|c|c|}
\hline \multicolumn{9}{|c|}{$\begin{array}{c}\text { TABLA No } 2 \\
\text { MEDIDAS DE TENDENCIA CENTRAL Y DE POSICIÓN PARA EL IMC Y PARACLÍNICOS AL } \\
\text { INICIO DEL TRATAMIENTO }\end{array}$} \\
\hline & $\begin{array}{c}\text { IMC } \\
n=55\end{array}$ & $\begin{array}{c}\mathrm{Hb} \\
\mathrm{n}=56\end{array}$ & $\begin{array}{c}\text { TG } \\
n=30\end{array}$ & $\begin{array}{c}C T \\
n=31\end{array}$ & $\begin{array}{c}\mathrm{HDL} \\
\mathrm{n}=25\end{array}$ & $\begin{array}{c}\mathrm{LDL} \\
\mathrm{n}=25\end{array}$ & $\begin{array}{c}\text { Creatinina } \\
n=26\end{array}$ & $\begin{array}{c}\text { Glucosa } \\
n=38\end{array}$ \\
\hline Promedio & 21,5 & 12,7 & 171,3 & 172,5 & 46,3 & 94,8 & 0,8 & 79,1 \\
\hline $\begin{array}{l}\text { Desviación } \\
\text { Estándar }\end{array}$ & $\pm 4,2$ & $\pm 1,8$ & $\pm 122,9$ & $\pm 50,3$ & $\pm 18,6$ & $\pm 34,3$ & $\pm 0,2$ & $\pm 9,5$ \\
\hline Mínimo & 20,2 & 13 & 139,5 & 164 & 42 & 92 & 0,74 & 78 \\
\hline Máximo & 15,0 & 6,8 & 43 & 54 & 6 & 23 & 0,4 & 63 \\
\hline Moda & 35,8 & 15,6 & 713 & 269 & 98 & ND* & 1,1 & 103 \\
\hline
\end{tabular}


Lamivudina Estavudina Kaletra 11,3\% y Lamivudina Abacavir Kaletra 8,1\%. La efectividad de estos esquemas, teniendo en cuenta la disminución del recuento de linfocitos T CD4 (+) y la carga viral, se muestra en la tabla 3. La efectividad de la TARGA teniendo en cuenta los parámetros anteriores muestra que existe una disminución estadísticamente significativa de la carga viral $(p=0,004)$, hecho que no ocurre con el recuento de los linfocitos T CD4 $(+)(p=0,070)$ (Figuras No 1 y Figura No 2). La proporción de efectividad general de la TARGA fue de 9,9\% para disminución del recuento de linfocitos T CD4 (+) y del 58,9\% para disminución de la carga viral (Figura No 3 ).

\begin{tabular}{|c|c|c|c|c|c|c|c|}
\hline \multicolumn{8}{|c|}{$\begin{array}{c}\text { TABLA No } 3 \\
\text { EFECTIVIDAD DE LA TERAPIA TARGA POR COMBINACIÓN DE ANTIRRETROVIRALES MAS } \\
\text { FRECUENTEMENTE UTILIZADOS }\end{array}$} \\
\hline & $\begin{array}{l}\text { TOTAL } \\
\mathrm{N}=62\end{array}$ & \multicolumn{2}{|c|}{$\begin{array}{l}\text { CD4(+) } \\
\mathrm{Me}(\mathrm{RI})\end{array}$} & \multirow[t]{2}{*}{$\begin{array}{l}\text { Valor } \\
\text { de } p\end{array}$} & \multicolumn{2}{|c|}{$\begin{array}{c}\text { Carga Viral } \\
\text { Me (RI) }\end{array}$} & \multirow[t]{2}{*}{$\begin{array}{l}\text { Valor } \\
\text { de } \mathrm{p}\end{array}$} \\
\hline & $\mathrm{N}$ & Antes & Después & & Antes & Después & \\
\hline $\begin{array}{l}\text { Todos los } \\
\text { esquemas }\end{array}$ & 100 & $\begin{array}{c}232 \\
(119-355)\end{array}$ & $\begin{array}{c}209 \\
(99,2-316,0)\end{array}$ & $0,070^{*}$ & $\begin{array}{c}6084 \\
(1191-47727)\end{array}$ & $\begin{array}{c}2503 \\
(843-16804)\end{array}$ & $0,004 *$ \\
\hline $\begin{array}{l}\text { Lamivudina } \\
\text { Estavudina } \\
\text { Nevirapina }\end{array}$ & 29,0 & $\begin{array}{c}254 \\
(174-377)\end{array}$ & $\begin{array}{c}282 \\
(149-391)\end{array}$ & $0,417 *$ & $\begin{array}{c}5423 \\
(1191-47000)\end{array}$ & $\begin{array}{c}1574,0 \\
(843-5150)\end{array}$ & $0,013 *$ \\
\hline $\begin{array}{l}\text { Lamivudina } \\
\text { Zidovudina } \\
\text { Efavirenz }\end{array}$ & 19,4 & $\begin{array}{c}371 \\
(212-418)\end{array}$ & $\begin{array}{c}286 \\
(118-344)\end{array}$ & $0,001 * *$ & $\begin{array}{c}3296 \\
(1641-18072)\end{array}$ & $\begin{array}{c}6331,0 \\
(999,5-19177)\end{array}$ & $0,850 *$ \\
\hline $\begin{array}{l}\text { Lamivudina } \\
\text { Estavudina } \\
\text { Kaletra }\end{array}$ & 11,3 & $\begin{array}{c}65 \\
(31,5-167)\end{array}$ & $\begin{array}{c}106 \\
(36,8-287)\end{array}$ & 0,218 & $\begin{array}{c}108400 \\
(15547-290186)\end{array}$ & $\begin{array}{c}1841 \\
(216-57313,5)\end{array}$ & $0,296 *$ \\
\hline $\begin{array}{l}\text { Lamivudina } \\
\text { Abacavir } \\
\text { Kaletra }\end{array}$ & 8,1 & $\begin{array}{c}147 \\
(119-321)\end{array}$ & $\begin{array}{c}144 \\
(95,3-253,5)\end{array}$ & $0437 *$ & $\begin{array}{c}2819 \\
(2068-27211)\end{array}$ & $\begin{array}{c}5562 \\
(2348-13927)\end{array}$ & $0,625 *$ \\
\hline
\end{tabular}

FIGURA NO 1

COMPRACION DE MEDIANAS PARA RECUENTOS DE LINFOCITOS TCD4 (+)
FIGURAS NO 2

COMPRACION DE MEDIANAS PARA RECUENTOS DE LA CARGA VIRAL
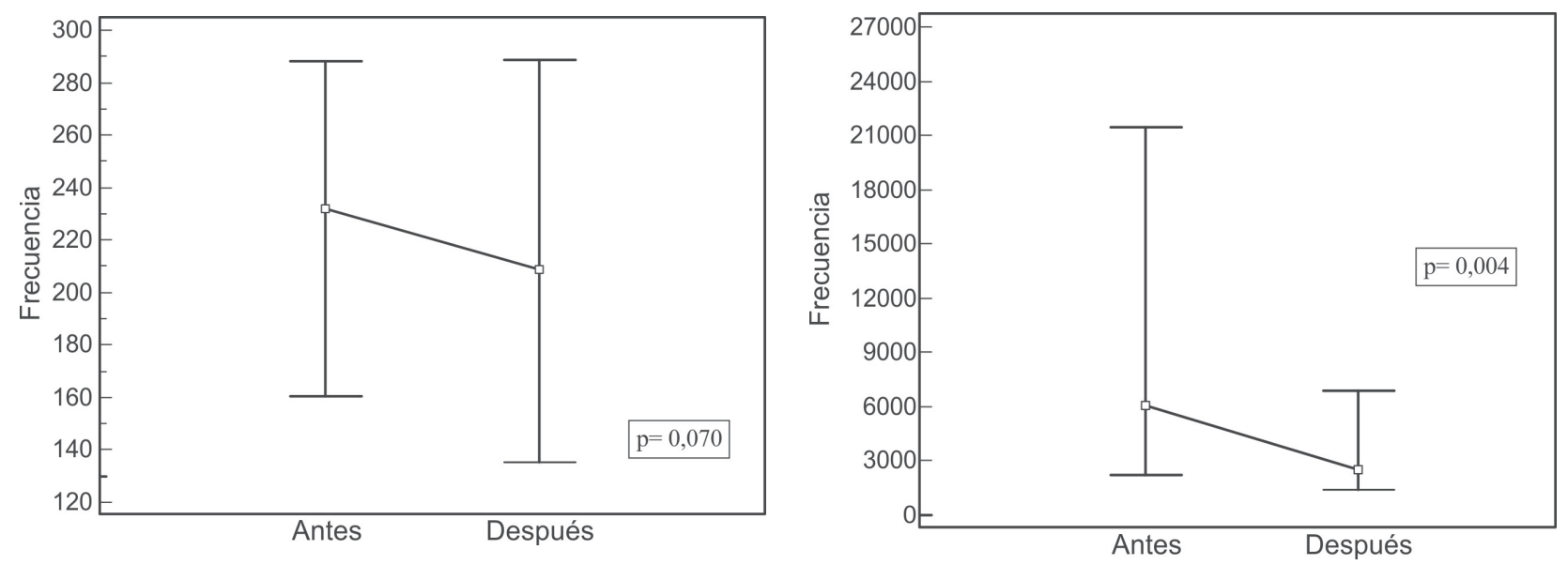
FIGURAS NO 3

PORCENTAJE DE EFECTIVIDAD DE LA

TERAPIA TARGA, POR ESQUEMAS MAS FRECUENTES UTILIZADOS

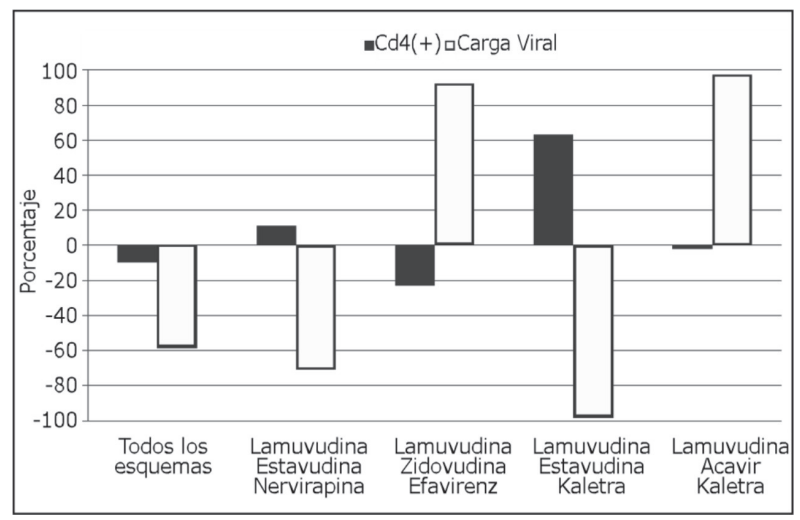

\section{DISCUSIÓN}

En Colombia se han reportado un total de 57.489 casos, incluyendo infecciones asintomáticas, casos de SIDA y fallecidos. Esta cifra corresponde a los casos acumulados con corte a noviembre de 2007 . El 76,6\% de los casos reportados con registro individual son hombres y el $22,1 \%$ son mujeres (la variable sexo no está reportada en el 1,2\% del total de las fichas de notificación). En los $34.504(59,1 \%)$ casos en que se reportó el mecanismo probable de transmisión, el $58,1 \%$ corresponde al comportamiento heterosexual y el $37,6 \%$ homosexual $y$ bisexual. El grupo poblacional más afectado agrupado por grupos quinquenales, es el de 25 a 29 años con 8.076 equivalentes al $20,0 \%$; en relación con los 40.335 registros con reporte de edad (70,2\%). El $57,7 \%$ se encuentra en el grupo de 15 a 34 años de edad, sin desconocer que en los últimos años, se evidencia un incremento de casos en los grupos mayores de 45 años con el 13,1\% de la participación. Igualmente, sobre los 57.489 casos reportados por ficha, se puede afirmar que el 3,3\% (1.873 casos) son menores de 18 años, de estos 1.085 casos corresponden a transmisión perinatal (2).

En 1996, diez años después del descubrimiento del VIH, se introdujo el concepto de tratar la infección por el VIH con terapia antirretroviral de gran actividad (TARGA). La cual utiliza una combinación de drogas antivirales con el fin de lograr la supresión permanente de la replicación del VIH y por lo tanto prevenir las consecuencias de una infección descontrolada en particular la pérdida de la inmunidad mediada por las células CD4. Las consideraciones teóricas, así como también la experiencia clínica, sugieren que la TARGA puede ser un método exitoso de tratamiento durante toda la vida en la mayoría de pacientes (5).

Aunque en algunas áreas del mundo parezca una meta distante disminuir la mortalidad asociada al VIH/SIDA, en otras regiones se ha hecho un gran progreso. Entre 1987 y 1994, por ejemplo el VIH/SIDA fue la principal causa de muerte en los Estados Unidos de América, con tasas de muerte que se incrementaban cada año hasta llegar a convertirse en la principal causa de muerte en jóvenes adultos. Con la llegada de las drogas antivirales, y especialmente la introducción de los inhibidores de proteasa a mediados de los años 90, la mortalidad asociada al VIH/SIDA comenzó a disminuir $(6,7)$. Esta tendencia también es evidente en otros países industrializados, y se comienza a observar tendencias similares en algunas naciones no industrializadas en las cuales se está manejando mejor la epidemia. La disminución de la mortalidad relacionada al SIDA es una señal alentadora de que las personas infectadas con el VIH están viviendo más y mejor (6).

La terapia antirretroviral de la infección por VIH ha convertido lo que antes era un padecimiento fatal en una enfermedad potencialmente crónica. Actualmente hay aproximadamente 17 drogas en uso común para el tratamiento del VIH. Los pacientes que tienen acceso y pueden adherir a la combinación de terapia deben ser capaces de alcanzar una supresión de la replicación del VIH que sea durable y eventualmente de por vida. Sin embargo, a pesar del incuestionable éxito de la terapia antirretroviral, aún hay limitaciones. El éxito del tratamiento requiere una adherencia estricta y de por vida, además, aunque las drogas usadas son generalmente bien toleradas, la mayoría tienen efectos tóxicos a corto plazo, y todas tienen el potencial de producir efectos adversos tanto conocidos como desconocidos a largo plazo. 
El costo de las drogas y de su administración, limita la posibilidad de tratamiento en lugares con escasos recursos, y actualmente hay una creciente preocupación al respecto, incluso en naciones con altos recursos. El control completo o parcial de la replicación viral no restaura completamente la salud del paciente, los pacientes que son tratados por largo tiempo, quienes tienen un régimen de tratamiento efectivo y frecuentemente muestran una disfunción inmune persistente; tienen un riesgo más alto de lo esperado de sufrir varias complicaciones no relacionadas con el estatus SIDA, como: afecciones del corazón, los huesos, el hígado, los riñones y enfermedades neurocognitivas (8).

Se conoce como TARGA a la combinación de 3 o 4 fármacos antirretrovirales que actúan en varias etapas del ciclo vital del VIH. Estas drogas pertenecen a 5 categorías diferentes, las cuales difieren en su mecanismo de acción, son: (A) inhibidores de transcriptasa reversa; (B) inhibidores de proteasa; (C) inhibidores de fusión; (D) inhibidores de entrada y $(E)$ inhibidores de la integrasa (9, 10).

(A) La transcriptasa reversa o inversa es una enzima viral que el VIH requiere para su reproducción. La inhibición de esta enzima impide el desarrollo de ADN viral basado en su ARN. Existen tres clases: Primero. Inhibidores análogos nucleósidos, entre los que se encuentran: Zidovudina (ZDV) un análogo de la timidina. Didanosina (DD) análogo de la adenosina. La Zalcitabina (DDC) análogo de pirimidina. Estavudina (D4T). Lamivudina (3TC) análogo de citidina. Abacavir $(A B C)$ análogo de guanosina. Emtricitabina (FTC) es análogo de citidina. Segundo. Inhibidores de transcriptasa no nucleósidos: Nevirapina, Efavirenz. Tercero. Inhibidores de transcriptasa análogos de nucleótido: Ios análogos nucleósidos se convierten en el cuerpo a nucleótidos, esto deriva en menor toxicidad y disminuye el tiempo de latencia del fármaco. Tenofovir disoproxil fumarato o tenofovir.

(B) Inhibidores de proteasa: La proteasa es una enzima requerida por el VIH para el ensamblaje final de los viriones, su inhibición resulta en inhibición de la replicación viral. entre estos fármacos se encuentran:
Saquinavir, Ritonavir, Indinavir, Nelfinavir, Lopinavir y Atazanavir.

(C) Inhibidores de fusión: estos fármacos impiden la entrada del virus a la célula previniendo la infección de células sanas entre ellos está la Enfuvirtida.

(D) Inhibidores de entrada: son anticuerpos dirigidos contra los co-receptores CCR5, que bloquean la unión de la GP120 al receptor de la célula y de esta forma el VIH no logra entrar a la célula, y esta se mantendrá intacta y continuará con sus funciones normales. Esto ofrece una gran ventaja, pues los actuales antirretrovirales actúan dentro de la célula cuando el VIH ya la ha infectado. Además, pueden ser bien tolerados por el paciente con pocos o ningún efecto secundario. Estos anticuerpos son una alternativa al tratamiento del VIH multiresistente, con tropismo al coreceptor CCR5 $(9,10)$.

(E) Inhibidores de la integrasa: son medicamentos que evitan la acción de la integrasa, selectivos únicamente al VIH-1. Son potentes antirretrovirales y se ha demostrado cierta eficacia como monoterapia. Entre ellos se encuentra: Raltegravir y Elvitegravir.

Recientemente se han introducido preparados que contienen varios principios activos en una sola cápsula o comprimido.

Con los actuales regímenes antirretrovirales no se puede alcanzar la completa erradicación de la infección por el VIH. Esto se debe principalmente a que el haz de células $T$ CD4 infectadas latentemente se establece durante las primeras etapas de la infección aguda por $\mathrm{VIH}$, y persiste con una larga vida media, incluso con supresión prolongada de la viremia plasmática $(11,12,13)$. Por lo tanto, las principales metas que guían la decisión de iniciar la terapia antirretroviral son: a) suprimir al máximo y durablemente la carga viral plasmática del VIH, b) reducir la morbilidad asociada al VIH y prolongar la supervivencia, c) mejorar la calidad de vida, d) restaurar y preservar la función inmune, y e) prevenir la transmisión del VIH (14).

La supresión del VIH con TARGA puede también disminuir la inflamación y la activación 
inmune que se piensa contribuye a las más altas tasas de co-morbilidades vasculares y de otro tipo que se reportan en pacientes infectados con el VIH. Una supresión máxima y durable de la viremia plasmática también retarda o previene la selección de mutaciones que confieren resistencia, preserva el número de células T CD4, y confiere beneficios clínicos sustanciales (15). Alcanzar una supresión viral máxima con la terapia inicial requiere el uso de regímenes de antirretrovirales con al menos dos y preferiblemente tres drogas activas de múltiples clases. Cuando no se alcanza inicialmente una supresión máxima o esta se pierde, se requiere entonces cambiar a un nuevo régimen con al menos dos drogas activas. El creciente número de drogas y clases de estas, hacen que la meta en todos los pacientes sea la supresión viral por debajo de los límites de detección, incluso en individuos con resistencia a las drogas, ya sea adquirida o primaria. La reducción de la carga viral por debajo de los límites de detección en pacientes que no han sido previamente sometidos a tratamiento, usualmente se da dentro de las primeras 12 a 24 semanas de terapia (14).

Existen varios predictores del éxito de la terapia, estos incluyen: alta potencia del régimen antirretroviral, excelente adherencia al régimen de tratamiento (16), baja viremia de base o inicial (17), conteo inicial de células CD4 mas altos (>200 cells/mm3) (18), y v) rápida reducción de la viremia en respuesta al tratamiento (19). Alcanzar las metas del tratamiento requiere algunas veces balancear consideraciones que pueden ser contradictorias. Los médicos tratantes y los pacientes deben trabajar juntos para definir estrategias individualizadas para lograr las metas del tratamiento (14).

Varios regímenes de preferencia o alternativos son recomendados. Muchos de estos regímenes tienen una eficacia comparable pero varían en algún grado en la frecuencia de las dosis, en el número de pastillas, la interacción entre las drogas, y los efectos colaterales potenciales. Un régimen debe adaptarse a cada paciente para aumentar la adherencia y así mejorar el resultado de la atención. La adaptación de cada régimen se basa en consideraciones como efectos colaterales esperados, conveniencia, comorbilidades, interacción con medicamentos concomitantes y, cuando están disponibles, evaluación genotípica de resistencia a las drogas antes del tratamiento. Otro factor importante en el éxito del tratamiento es la adherencia, pues una adherencia subóptima puede resultar en una reducida respuesta al tratamiento. Una adherencia incompleta se puede pre-sentar como resultado de regímenes de medicamentos demasiado complejos, factores asociados al paciente como abuso activo de sustancias y depresión, problemas con los sistemas de salud; incluyendo interrupciones en el acceso a los medicamentos e inadecuada educación sobre el tratamiento y apoyo. Las condiciones que promueven la adherencia se deben maximizar antes y después de la iniciación de la terapia antirretroviral (14).

Un número de exámenes de laboratorio son importantes para la evaluación inicial de un paciente infectado con el VIH. Cuando se entra a un programa de atención, durante el seguimiento si la terapia aun no se ha iniciado, y antes y después del comienzo de esta o el cambio de terapia para evaluar la eficacia virológica e inmunológica de la TARGA, así como también monitorear anormalidades de laboratorio que puedan estar asociadas con la terapia. Rutinariamente se utilizan dos marcadores para evaluar la función inmune y los niveles de viremia del VIH: el conteo de células CD4 y la carga viral (RNA plasmático del VIH). Cuando está disponible, se debe usar un test de resistencia para guiar la selección del régimen antirretroviral tanto en pacientes que no han sido sometidos a tratamiento como en los que ya han sido tratados. Otros exámenes se recomiendan pero su utilidad se ve limitada por la disponibilidad de tecnologías para su realización en lugares con escasos recursos, estos son: ensayo de tropismo viral antes de iniciar una terapia con antagonistas del receptor CCR5, y test de HLA-B*5701 antes de iniciar terapia con Abacavir (14).

La carga viral (RNA del VIH en plasma) se debe medir en todos los pacientes como análisis de base y luego regularmente, especialmente en pacientes que están en tratamiento, porque la carga viral es el indicador más importante de respuesta a la terapia antirretroviral. Diferentes estudios 
han demostrado una asociación significativa entre la disminución de la carga viral y la mejoría en los resultados clínicos (15). Por tal motivo, la carga viral sirve como un marcador de respuesta al tratamiento y puede ser útil en la predicción de la progresión clínica (16, $17,18)$. El cambio mínimo que es considerado significativo es uno de tres veces en la carga viral (2 desviaciones estándar), o un cambio de $0.5 \log ^{10}$ copias $/ \mathrm{ml}$. Una meta clave de la terapia es la supresión de la carga viral por debajo de los limites de detección (debajo de 40-75 copias/ml en la mayoría de ensayos disponibles comercialmente). La supresión de la carga viral generalmente se logra entre 12 y 24 semanas en la mayoría de pacientes que adhieren a su régimen antirretroviral y quienes no albergan mutaciones que confieran resistencia a las drogas prescritas, aunque en algunos pacientes puede tomar más tiempo.

Las siguientes son las recomendaciones de la frecuencia con la que se debe monitorear la carga viral $(2,14)$ :

En este estudio los esquemas utilizados de TARGA son acordes a los sugeridos por las guías de manejo de VIH, nacionales e internacionales $(2,19,20)$.

La efectividad de estos esquemas es más baja que la reportada por estudios en Europa y Estados Unidos $(5,8)$. Las diferencias marcadas en cuanto a la disminución del recuento de linfocitos CD $4(+)$ y carga viral, por esquema de TARGA utilizado, puede deberse a la estratificación de la muestra estudiada, lo que puede estar subestimando el efecto real de los medicamentos en los pacientes.

Estos hallazgos pueden ser producto, en primera instancia, de la limitación del sistema de salud en el suministro de los medicamentos antirretrovirales, en la vigilancia y el control de su administración. El diseño retrospectivo del estudio posee información limitada sobre el tiempo de evolución de la infección por VIH de cada uno de los pacientes, hecho que también sustenta la disminución de la efectividad de esta terapia farmacológica en nuestro medio.

Finalmente, la presente investigación brinda herramientas importantes que sugieren los puntos álgidos de la atención al paciente con VIH como son: suministro y administración de antirretrovirales, apego al tratamiento por parte de los pacientes y evaluación de la efectividad de las terapias sugeridas como primera línea de tratamiento. Por todo lo anterior los autores recomiendan realizar estudios prospectivos que evalúen los esquemas específicos para mejorar la calidad de las estimaciones.

\section{CONCLUSIÓN}

La evaluación de la terapia antirretroviral en el paciente con VIH/SIDA es un punto neurálgico de la atención del pacientes y al mismo tiempo el menos estudiado. Se pretende resaltar este tema e invitar a los interesados a realizar estudios prospectivos al respecto, los cuales incidirán positivamente en la salud de los pacientes, asignación de recursos gubernamentales, iniciativas encaminadas a la vigilancia y control de estos programas y reestructuraciones de los mismos.

CONFLICTOS DE INTERÉS: ninguno que declarar.

FINANCIACIÓN: recursos propios de los autores.

\section{REFERENCIAS BIBLIOGRÁFICAS}

1. Ministerio de la Protección Social. Plan nacional de respuesta ante el VIH y el SIDA. Colombia 2008-2011 Bogotá D. C. Enero de 2008.

2. Ministerio de la Protección Social. Guía para el manejo de VIH/SIDA basada en la evidencia Colombia. 2003.

3. Joint United Nations Programme on HIV/AIDS (UNAIDS). 2008 Report on the Global AIDS Epidemic. Geneva, Switzerland: World Health Organization; 2008.

4. Calleja JM, Walker N, Cuchi P, et al. Status of the HIV/AIDS epidemic and methods to monitor it in the Latin America and Caribbean region. AIDS 2002;16(suppl):S3-S12.

5. Vogel M, Schwarze-Zander C, Wasmuth JC, Spengler U, Sauerbruch T, Rockstroh JK. The 
